\title{
LAS CONDICIONES OBJETIVAS DE PUNIBILIDAD Y SU TRATAMIENTO PROCESAL EN EL PERU
}

\section{César Eugenio San Martín Castro}

\section{A. PLANTEAMIENTO DEL PROBLEMA}

Ya en los años 50 el profesor Edmund Mezger, de la Universidad de Munich, expresaba respecto a las condiciones objetivas de punibilidad que "se trata de un punto muy confuso y debatido" (1958: 241). Inclusive, mucho antes, en el año 1931 Jimenez de Asúa hacía mención o recordaba la confusión reinante en este asunto (1970, VII: 47). De igual forma, en el Perú el Dr. Peña Cabrera haciéndose eco del estado de la dogmática sobre el particular advertía que el tema "es borrascoso" pues la doctrina no ha determinado (su exacta estructura juridica" (1977: 208). Sin embargo, contemporáneamente gracias a los avances de la dogmática alemana se va imponiendo gradualmente un consenso doctrinario acerca de su naturaleza jurídica, su necesidad y su radicación definitiva en el derecho penal material (Jescheck, Stratenwerth, Schmidt, Bemmann, Bockelmann, ... etc).

Igualmente, en forma paralela a esa institución, el debate doctrinario se ha centrado a delimitar la naturaleza y efectos jurídicos de las condiciones de perseguibilidad o procesabilidad, distinguiéndolas con ayuda del concepto de los presupuestos procesales, estudiados precursoramente por Oscar Bulow en 1868, de las condiciones objetivas de punibilidad.

Esta última tiene especial trascendencia práctica en nuestro ordenamiento procesal por cuanto a partir de la promulgación del D.L. 21895, del dos de agosto de 1977, se reconoció a las "cuestiones previas" como medio específico de defensa técnica, aunque ya la jurisprudencia suprema las admitía, tendiente a cautelar la correcta perseguibilidad de la acción penal, pero otorgándole el carácter equívoco de cuestión pre-judicial o excepción de naturaleza de juicio (García Rada, 1980: 28; Del Valle, 1966: 101-102). 
La total autonomía, unánimemente reconocida, que tiene el Derecho Procesal Penal obliga pues a un análisis muy puntual respecto a sus relaciones con el Derecho Penal Material, y en especial entre condiciones de punibilidad y de procedibilidad, porque de su exacta definición y concreción metodológica dependerá concluir si existe igualdad esencial entre ambos conceptos, como postulan Hilde Kaufmann en Alemania y Zaffaroni en Argentina, entre otros, o si - por el contrario-son instituciones diferentes y diferenciables, cuyo tratamiento procesal en cuando medio de defensa se realizará como cuestión previa, siguiéndose los dictados de la jurisprudencia y de la doctrina nacional, o como excepción de naturaleza de acción, que es el punto central de nuestra sugerencia.

Por consiguiente, la óptica del presente trabajo es eminentemente práctica y tiende a tratar de esclarecer, en lo que es posible, si la ausencia de una condición objetiva de punibilidad determina la proposición con éxito de una cuestión previa o, más bien, obliga a la deducción de una excepción de naturaleza de acción. Para ello es menester estudiar, de modo muy conciso, todas las instituciones que de uno $u$ otro modo se relacionan con el tema en cuestión; esclareciéndose como corolario final si la condición objetiva de punibilidad es una institución procesal y por ende debe relacionarse directamente con la cuestión previa.

\section{B. CONDICION OBJETIVA DE PUNIBILIDAD}

El maestro Jiménez de Asúa, dando cuenta del inicio de esta institución, explicaba que aquéllas “... surgen como ex cepción del parágrafo 59 del Código Penal Alemán”, correspondiendo su tratamiento orgánico como institución autónoma al profesor Ernst Von Beling en el año 1906 (1976: 417). Actualmente el Código Penal Italiano de 1930, en su Art. 44, tiene consagrada dicha institución, no así nuestro Código Penal de 1924, ni los sucesivos proyectos modificatorios que se han venido publicando a partir del año pasado; situación que obliga a un tratamiento exclusivamente dogmático sin referencia a la parte general de nuestro Código.

Stratenwerth nos dice que la culpabilidad jurídico-penalmente captable no justifica por si sola la pena y que en todos los 
casos deberá agregarse todavía la necesidad práctica de hacer uso de la pena para la protección del orden social (1982: 72). Es decir, que la tipicidad, la antijuridicidad y la culpabilidad no son suficientes para imponer una pena, y que hay determinados comportamientos en que la imposición de una sanción resultan fundamentadas por circunstancias externas a esos elementos.

Se define las condiciones objetivas de punibilidad, siguiendo a Jeschek, como "las circunstancias que se encuentran en relación inmediata con el hecho, pero que no pertenecen ni al tipo de injusto ni al de culpabilidad" (1981, II; 763). Como tal el autor no es punible si no se realiza la condición de punibilidad, ni siquiera en grado de tentativa, porque ella supone necesariamente la verificación de la condición (Maggiore, I: 282).

Como las condiciones de punibilidad son causas de restricción de pena que se exigen en determinados casos por razones de política criminal, estatuidas expresamente por el legislador, es que no pertenecen al tipo de injusto y son externas a él. Es por ello que actualmente es inatendible la afirmación que en 1931 diera Jiménez de Asúa en el sentido que aquéllas no existen pues son elementos normativos o modalidades del tipo cuya ausencia destruye la tipicidad; posición que por lo demás el Maestro español varió radicalmente en 1970 al publicar el Tomo VII de su monumental Tratado de Derecho Penal. Las condiciones objetivas de punibilidad son otros de los presupuestos de la punibilidad, de tal suerte que no es preciso que sean abarcadas por la culpabilidad y su producción es indiferente al lugar y tiempo de la acción.

La vigente doctrina alemana distingue dos grandes grupos de casos: las condiciones de punibilidad propias y las impropias. Las primeras son puras causas de restricción de pena: al injusto y culpabilidad se niega la sanción en la medida en que no se adiciona otra circunstancia que afecte al hecho, otorgándole una mayor significación en su relación con su entorno. Las segundas, sobre las que existen serias objeciones y cuya conceptuaclón debe abordarse tentativamente, se dividen en dos sub-grupos: a) causas de agravamien to encubiertas, que si bien pertenecen al tipo de injusto, para apartarlas de las exigencias de culpabilidad se consignan como tal; y, b) circunstancias de hecho enmascaradas que fundamentan la pena. 
Dentro de la dogmática nacional ni Bramont ni Peña han cuestionado su existencia. Bramont las trata dentro de los elementos del delito y menciona que "constituyen hechos externos desvinculados de la acción típica, pero necesarios para que pueda aplicarse la pena" (1966: 18). Peña anota que la condición objetiva de punibilidad es una consecuencia del delito y no un elemento constitutivo del mismo, y - siguiendo a Etcheberry- la define como "determinados acontecimientos ajenos a la acción misma del hecho, y por lo común no dependientes de su voluntad, pero que tocan a ese hecho de la relevancia jurídica que la ley considera indispensable para que se justifique la sanción" (1977: 208209).

Aclarando el problema anotado entre ambos autores nacionales, es decir entre elemento y consecuencia del delito, diremos siguiendo a Stratenwerth que la punibilidad de un comportamiento depende de las exigencias de la legalidad de la amenaza penal, de la limitación al comportamiento reprochable y del principio que sólo es justificable la pena en cuanto aparece político-criminalmente como ineludible, punto último donde se encuentran las condiciones de punibilidad; que estos tres grandes rubros articulan los presupuestos de la punibilidad y que ordenados sistemáticamente en sí constituyen la estructura del delito.

El profesor Zaffaroni expresa, por su parte, que la punibilidad no pertenece a la esfera del delito y que, en rigor, las condiciones objetivas de punibilidad son elementos del tipo objetivo que, como tales, deben ser abarcados por el conocimiento (dolo) o por la posibilidad de conocimiento (culpa); en su Manual de Derecho Penal trata esta institución denominándola "condiciones de operatividad de la coerción penal" (1980: 557 y ss.)

Sobre el particular ya nos hemos pronunciado párrafos atrás, debiendo agregar que un concepto descriptivo-normativo del delito referido a nuestro Código Penal, como lo resalta Hurtado Pozo, obliga a hacer mención a la punibilidad (1978: 199-200). Jiménez de Asúa resalta que el estar penado es una característica específica del delito, pues aquél no se completa aunque esté perfecto el tipo si es que no se configura la condición extrínseca a él exigida por la ley en determinados casos (1970: VII: 49).

Analizando nuestro ordenamiento penal y correlacionándola 
con la parte especial de esta institución, tenemos las siguientes condiciones objetivas de punibilidad:

a) Artículo 5 inc. 2o. del C.P.: delitos cometidos por peruanos en el extranjero.

b) Artículo 212 del C.P.: exigencia de divorcio por razón de adulterio en el delito de adulterio.

c) Artículo 252: exigencia de la declaración de quiebra en el delito de quiebra fraudulenta.

d) Artículo 157: castigo de la incitación al suicidio cuando se consume o intente.

e) Artículo 310: necesidad de que la conspiración sea descubierta antes de ponerse en ejecución.

f) Artículo 311: exigencia que la rebelión o sedición lleguen a tener efecto para la punibilidad agravada de la seducción de tropas.

Bramont, al igual que Soler (1983, II: 199), da cuenta en contraposición a lo afirmado por Peña, que las exigencias de los artículos 212 y 252 del C.P. son meros presupuestos procesales. Sobre este punto nos pronunciaremos más adelante.

\section{CONDICIONES DE PROCEDIBILIDAD}

Partiendo de la premisa esencial de la independencia del Derecho Procesal Penal frente al Derecho Penal Material, dado que vive en la realidad con normas propias y principios rectores (Clariá Olmedo, 1960, I: 56), se debe puntualizar que aún cuando éste sirve para la realización del derecho penal material vista su accesoriedad, no puede confundirse con aquél y por ello no puede haber trastrueque entre sus instituciones, como sería entre las condiciones objetivas de punibilidad y las condiciones de perseguibilidad o procedibilidad.

La premisa para abordar las condiciones de procedibilidad es el estudio de lo que Oscar Bulow denominó "presupuestos proce- 
sales". El profesor Alzamora Valdez define los presupuestos procesales como "aquéllos que se requieren para que exista válidamente la relación procesal, que son: la competencia del Juez, la capacidad de las partes y el cumplimiento de los requisitos de forma y presentación de la demanda" (1974: 236). Ahora bien; como tal, comprende la totalidad de las condiciones de las cuales depende que un proceso puede obtener una sentencia sobre el fondo respecto a un determinado objeto del mismo; y, siguiendo a Schmidt, aquéllos resultan, en parte, en relación a los sujetos procesales, y, en parte, de las relaciones del objeto del proceso con el procedimiento concreto cuya admisibilidad como camino para la sentencia se pone en cuestión (1957: 82-83).

La distinción, por tanto, es muy marcada entre condición objetiva de punibilidad y presupuesto procesal. La primera pertenece a los presupuestos de la punibilidad y la segunda son circunstancias que se oponen a la instauración de una relación procesal válida. Cuando falta una condición objetiva procede la absolución y cuando falta un presupuesto procesal el proceso se detiene (Jescheck, II, 1981: 767).

El artículo $4^{\circ}$, 2do. pf., del C.P.P., mod. por el D-Leg. 126, hace mención expresa a la cuestión previa y precisa que ésta procede cuando la acción penal se ejerce no concurriendo un requisito de procedibilidad; siendo así, dentro de nuestro ordenamiento procesal penal este medio de defensa incide en el presupuesto procesal relativo a la forma y presentación de la denuncia, a las condiciones de admisibilidad del acusador y a la forma del planteamiento de la denuncia. Como expone Schmidt "se trata de establecer si una acción conforme a las condiciones de admisibilidad, abre la vía para una sentencia" (1957: 91).

El profesor García Rada, citando a Leone precisa que las condiciones de procedibilidad son "aquéllas causas que condicionan el ejercicio de la acción penal y sin cuya presencia no es posible promover o proseguir la acción penal". (1980: 29). Bajo ese orden de ideas, Maggiore nos dice que "son aquéllos sucesos que sobrevienen al hecho y que sin influir en la punibilidad o existencia del delito, constituyen un obstáculo para comenzar o proseguir la acción penal (1972, I: 282).

Siguiendo esos conceptos el propio Garcia Rada se contra- 
dice al afirmar que la realidad de la condición de procedibilidad fluye de los requisitos del delito, por cuanto -como ya se dejó sentado- aquél incide en la validez de un proceso penal y no en la punibilidad de una conducta. De igual manera incurren en error, de un lado, Urtecho Benites al afirmar que "extraprocesalmente la cuestión previa está contemplada como condición objetiva de penalidad en las normas de la parte especial del Código Penal, o en otra ley especial" (1978: 145); y, de otro lado, Del Valle al sostener que "la cuestión previa se plantea cuando al hecho le falta un elemento objetivo de punibilidad" (1966: 103). En efecto; la cuestión previa como institución procesal no cabe describirla en tipos determinados del Código Penal, además no se puede identificar o confundir condiciones de perseguibilidad y de punibilidad. Las primeras son: "condiciones para la iniciación del proceso" (Bramont, 1964: 38); y, las segundas, circunstancias ajenas o exteriores al delito, independientes de la voluntad del agente, que determinan la punibilidad del mismo (Cuello Calón, 1961: 522).

Tratándose de concretos presupuestos procesales para la iniciación de la acción penal, tanto el Código Penal como el Código de Procedimientos Penales, regulan las siguientes:

a) Querella Penal: tratándose de los denominados 'delitos privados' (art. $2^{\circ}$ del C.P.P., art. 18 inc. $2^{\circ}$, del C.P.). Como ejemplos tenemos: determinados casos de delitos culposos (art. 168 C.P.), delitos contra el honor personal (art. 195 C.P., art.302 C.P.P.) determinados delitos contra el honor sexual (art. 205 C.P.), delitos de adulterio (art. 212 C.P.), delitos de amenaza (art. 224 C.P.), delitos de someter a una persona a situación análoga a la servidumbre (art. 225 C.P.), delitos de violación de domicilio (art. 230 C.P.), delitos de violación del secreto de correspondencia (art. 235 C.P.) y delitos de violación del secreto de empleo y profesión (art. 363 C.P.). En las leyes especiales tenemos los delitos de autor (Ley 13714) y delitos de abandono de familia (art. 40 de la Ley 13906).

b) Autorización para proceder: fijada en determinados delitos contra el honor sexual. Se requiere ratificación de la denuncia ante el Juez para el procedimiento del autor con intervención del Ministerio Público (art. 313 del C.P.P.). 
c) Ante Juicio Constitucional tratándose de Parlamentarios, Ministros, Miembros de la Corte Suprema y del Tribunal de Garantías Constitucionales (arts. 183 y 184 Const.), así como Fiscales Supremos (art. 15 del D-..Leg. 52).

d) Delitos de función cometidos por Fiscales, Jueces y Vocales: art. 66 incs. 2 y 4 del D-Leg. 52. La Ley establece un trámite especial.

\section{JURISPRUDENCIA NACIONAL}

Uniformemente la Jurisprudencia ha estimado tratándose del delito de adulterio que es cuesitón prejudicial la dilucidación previa de la acción civil por causal de adulterio (Ejecutorias Supremas de fechas siete de abril de 1941, veintiuno de setiembre de 1942, cuatro de mayo de 1945, ocho de abril de 1946 y 20 de Mayo de 1950); claro está que esas resoluciones supremas se expidieron antes de la promulgación del Decreto Ley 21895 , y no hemos encontrado resoluciones posteriores a esa norma legal, de modo que desconocemos cuál es el temperamento actual del Tribunal Supremo al respecto, debiendo relievarse que a raiz de la vigencia del Decreto-Legislativo 124 del mencionado delito está sujeto al trámite sumario y ya no puede ser de conocimiento del Tribunal Supremo.

En lo atinente al delito de quiebra la Corte Suprema ha amparado las excepciones de naturaleza de acción deducidas por los imputados ante la ausencia de la resolución declaratoria de quiebra (Ejecutorias Supremas de fecha nueve de junio de 1937 y veinticinco de julio de 1964), aunque igualmente dichas resoluciones se dictaron antes del Decreto-Ley pre-citado, por lo que al no conocerse ejecutorias dictadas durante su vigencia no es posible precisar la opinión actual de los Jueces Supremos.

Como ya lo hemos anotado, esas exigencias relativas al juicio civil pertinente constituyen condiciones objetivas de punibilidad $y$ no de procedibilidad, por lo que no pueden resolverse en vía de cuestión previa, como apuntan -entre autores nacionales recientes Urtecho Benites (1978: 146 y 149), Villagaray Hurtado (1981: 100-104) y Mixán Mass (1984, III: 122-125), donde es palmaria la confusión entre ambos conceptos. 
El profesor Roy Freire aún cuando da cuenta que la exigencia del divorcio civil es condición objetiva de punibilidad, precisa que "en el proceso penal su denominación técnica es la de cuestión previa" (1975, II: 198); y, en cuanto a la quiebra, acota que es una condición previa de procedibilidad (III, 1983: 288); de tal suerte que, a fin de cuentas, en cuanto al tratamiento procesal de aquéllas, concuerda con Bramont al considerar esas dos exigencias como condiciones de procesabilidad o presupuestos de procesabilidad (1966: 18).

Las resoluciones del fuero civil materia de ambos delitos no obstaculizan el ejercicio de la acción penal, sino que son puras causas de restricción de pena, que se hallan fuera del injusto y de la culpabilidad. Esta opinión concuerda con la reciente dogmática alemana citada por Jescheck, la española citada por Mir Puig (traducción de la obra del autor antes mencionado, páginas 770 y 771), y la Italiana citada por Maggiori; en igual sentido se pronuncian Cuello Calón, (1961: 523) y Schmidt (1957: 104). Jimenez de Asúa al sostener que "nos hallamos, pues, en presencia de una de esas condiciones extrínsecas, independientes del tipo penal de las que la ley punitiva ha hecho depender la efectividad de la pena (1970, VII: 60 y 67), las considera conceptualmente como condición objetiva de punibilidad; empero, adopta una clasificación un tanto discutible, pues nos dice que existen auténticas condiciones de punibilidad y condiciones de perseguibilidad que actúan como condición objetivas de punibilidad, consignando los dos delitos estudiados dentro de estas últimas; dudosa clasificación pues pretende homologar un instituto de derecho procesal penal dándole efectos de uno de derecho penal material, aún cuando en rigor, por el concepto que arriba de ellas y por su colocación dentro del amplio campo de aquéllas, no puede a mover a interrogantes sobre su real naturaleza jurídica.

Respecto al delito de estafa en la modalidad de giro de cheques sin fondos, en la que siguiendo la ley de la materia (Ley No. 16587, art. 165), se exige el protesto o constancia del Banco de no pagado por falta de fondos, el Supremo Tribunal ha considerado que su ausencia determina la inexistencia del delito, por lo que uniformemente ha declarado fundada las excepciones de naturaleza de acción deducidas (Ejecutorias Supremas de nueve de julio de 1938 y de quince de febrero de 1973). Igualmente, no exis- 
ten resoluciones dictadas con posterioridad al D.L. No. 21895 , de consiguiente, se desconoce si la Corte Suprema podría considerar ese supuesto como presupuesto procesal o condición de perseguibilidad. García Rada (1980: 29), así la considera; y, Urtecho, Villagaray y Mixán, le dan un tratamiento procesal de cuestión previa.

Nosotros, en cambio, siguiendo a Jiménez de Asúa (1970, VII: 97) y a Roy Freire (1983, III: 163), estimamos que ese requisito es una condición objetiva de punibilidad, pues se trata de una circunstancia anexa exigida por la ley para hacer funcionar la penalidad. No se trata de un obstáculo a la iniciación de la acción penal sino de una exigencia para penar una conducta típica.

En lo concerniente al delito de abandono de familia (art. $5^{\circ}$ de la Ley 13906), en que se exige una resolución que señale asignación provisional de alimentos o sentencia en el juicio correspondiente, el Tribunal Supremo ha estimado que si ello falta no cabe abrir instrucción y, en su caso, ha declarado la nulidad de lo actuado en la instrucción (Ejecutorias de fechas veintiuno de noviembre de 1966 y de dieciseis de enero de 1976). Por tanto, es claro que le da el carácter de condición de perseguibilidad, concordando en ello los tres autores antes indicados.

Bajo la misma línea conceptual que en los artículos 212 y 252 del C.P. (delitos de adulterio y quiebra fraudulenta), creemos que estamos ante una propia condición objetiva de punibilidad, por cuanto se condiciona el castigo al autor a la existencia de un juicio civil de alimentos y al requerimiento respectivo, al igual que en los prenotados es necesario una sentencia de divorcio y un auto declarativo de quiebra. En puridad ello no significa que no se ha incurrido fácticamente en abandono de familia, adulterio y quiebra fraudulenta, sino que para imponer una sanción la ley por razones de limitación de pena exige una circunstancia externa, esto es, un QUID PLURIS como dice Alemena.

Por último, en los delitos de falso testimonio derivado de un proceso penal (art. 334 del C.P.), el art. 257 del C.P.P. estatuye que con la sentencia se establecerá si procede abrir instrucción contra él. La Jurisprudencia se ha limitado a sostener que la declaración judicial es la que da pie al proceso por perjuicio 
y mientras ello no suceda no procede iniciar la acción penal (Ejecutoria de fecha 28 de agosto de 1905). Empero, como no define su real naturaleza juridica, ha dado pie a interpretaciones que consideran ese requisito como condición de perseguibilidad (Villagaray, 1981: 100 y Mixán, 1984: 145). Nosotros juzgamos que toda exigencia anexa al tipo y que condiciona la penalidad fijada en la ley constituye una condición objetiva de punibilidad; en el presente caso, no habrá delito que sancionar mientras que en otro proceso no se decida la apertura de instrucción contra el testigo por lo que en puridad estamos ante una condición objetiva de punibilidad.

En resumen, la jurisprudencia y la doctrina nacional no han diferenciado con todo rigor las condiciones objetivas de punibilidad y las condiciones de procedibilidad, procesabilidad o perseguibilidad; y, en el grueso de los casos, a nivel procesal se les ha dado un tratamiento errático al identificárselas. En este punto la doctrina ha avanzado más que la jurisprudencia, que no se ha esforzado en los casos que tuvo a su conocimiento en definir y clarificar ambos conceptos. Los estudios de la materia han intentado realizar una sistematización de las condiciones objetivas de punibilidad, no obstante lo cual, equivocadamente a nuestro criterio, le han dado un sitio dentro de los presupuestos procesales que condicionan el ejercicio de la acción penal.

Por consiguiente, habiéndose delineado con la claridad que nos ha sido posible la naturaleza y diferencias entre ambas instituciones, cabe afirmar de modo rotundo que el medio de defensa técnico a proponerse cuando se abre instrucción incumpliéndose la realización de la condición objetiva de punibilidad prevista expresamente en la Ley no es la cuestión previa sancionada en el segundo párrafo del artículo $4^{\circ}$ del C.P.P., modificado por el $\mathrm{D}$ Leg. No. 126, que está referida exclusivamente a la falta de una condición de perseguibilidad de la acción penal, más no a la ausencia de una condición objetiva de punibilidad.

Consideramos que tratándose del incumplimiento de una condición objetiva de punibilidad lo procedente es deducir una excepción de naturaleza de acción, prevista en el tercer párrafo del art. 5o. del C.P.P. Dicha excepción procede en dos casos: a) cuando el hecho denunciado no es justificable penalmente. Bramont señala que el primer caso se presenta cuando falta de modo 
absoluto la descripción típica; y, el segundo caso, cuando no concurre en un hecho concreto todos los elementos del tipo descrito en la Ley penal (1982: 28). Respecto a este último caso, Mizán Mass sostiene que se trata de un acto meramente típico pero al que la propia ley penal le quita expresamente la punibilidad (1984, III: 46-47).

Siguiendo este último concepto, que guarda estricta armonía con el texto de la Ley, nos inclinamos a sostener que, como la condición objetiva de punibilidad afecta la sanción del hecho delictuoso, el medio de defensa viable es precisamente la aludida excepción en su segundo extremo, esto es, que el hecho denunciado no es justiciable penalmente. Concordamos con Mixán Mass en el concepto que propone por cuanto los elementos del tipo se tienen que dar en su integridad para que exista prima facie delito, de tal suerte que no habría diferencia fundamental que justifique la división de la Ley en dos casos distintos en la fórmula de Bramont. En ese orden de ideas, la penalidad, a que se refiere el texto de la Ley, se afecta tanto por las condiciones objetivas de punibilidad como por las excepciones personales a la punibilidad, divididas en causas personales de exclusión de la pena y de levantamiento de la misma, denominadas en el derecho español siguiendo a Silvela "excusas absolutorias", terminología que ha sido recepcionada por nuestro derecho. 


\section{BIBLIOGRAFIA}

1. Edmund Mezger: Derecho Penal, Tomo I, Editorial Bibliográfica Argentina, Buenos Aires, 1958.

2. Luis Jiménez de Asúa: Tratado de Derecho Penal, Tomo VII, Editorial Losada, S.A., Buenos Aires, 1976.

3. Luis Jimenez de Asúa: La Ley y el Delito, Editorial Sudamericana, 7a. Edición, Buenos Aires, 1976.

4. Raúl Peña Cabrera: Derecho Penal Peruano - Parte General, Editorial Sesator, Lima, 1977.

5. Domingo García Rada: Manual de Derecho Procesal Penal. 6a. Edición, Editorial Sesator, Lima, 1980.

6. Luis del Valle Randich: Derecho Procesal Penal - Cuestiones prejudiciales, cuestiones previas, excepciones. Imprenta Liurimsa, Lima, 1966.

7. Günter Stratenwerth: Derecho Penal - Parte General, Tomo I, Editorial EDERSA, Madrid, 1982.

8. Hans-Heinrich Jescheck: Tratado de Derecho Penal - Parte General, Volumen II, Editorial Bosch, Barcelona, 1981.

9. Giuseppe Magiorre: Derecho Penal, Volumen I, Editorial Temis, Bogotá, 1971.

10. Luis Bramont Arias: Código Penal Anotado, Editorial "E1 Ferrocarril", Lima, 1966.

11. Luis Bramont Arias: Revista Advocatus, Año 3, Número 3, Lima, 1964. "Las excepciones procesales penales".

12. Luis Bramont Arias: Revista El Magistrado, $1^{\circ}$ Semestre, 
Lima, 1982. "Significado de la excepción de naturaleza de. acción en el proceso penal".

13. Eugenio Raúl Zaffaroni: Manual de Derecho Penal - Parte General, Editorial EDIAR, 3a. Edición, Buenos Aires, 1982.

14. José Hurtado Pozo: Manual de Derecho Penal - Parte General, Editorial Sesator, Lima, 1978.

15. Sebastián Soler: Derecho Penal Argentino, Tomo II, 9a. Reimpresión, Editorial TEA, Buenos Aires, 1983.

16. Jorge Clariá Olmedo: Tratado de Derecho Procesal Penal, Tomo I, Edición, Editorial EDIAR, Buenos Aires, 1960.

17. Mario Alzamora Valdez: Derecho Procesal Civil - Teoría del Proceso Civil, 5a. Edición, Editorial Sesator, Lima, 1974.

18. Eberhard Schmidt: Derecho Procesal Penal. Editorial Bibliográfica Argentina, Buenos Aires, 1957.

19. Santos Urtecho Benites: la cuestión prejudicial en el proceso penal, Imprenta Universidad Nacional de Trujillo, 1978.

20. Eugenio Cuello Calón, Derecho Penal, Tomo I, 9a. Edición, Editorial Nacional, México D.F., 1961.

21. Raúl Villagaray Hurtado: Cuestiones prejudiciales y previas en la ju risprudencia nacional, Editorial Sesator, Lima, 1981.

22. Florencio Mixán Mass: Derecho Procesal Penal, Tomo III, Ediciones Juridicas, Trujillo, 1984.

23. Luis Roy Freire: Derecho Perral Peruano, Tomo II, Editoriales Unidas. S.A., Lima, 1975.

24. Lu is Roy Freire: Derecho Penal Peruano, Tomo III, Editoriales Unidas, S. A., Lima, 1983. 